\title{
Symptomatic prostatic utricle: various approaches for treatment
}

\author{
Manjiri S. (D), Kush Luthra, Padmalatha S. K., Jeevak Shetty and Neehar Patil
}

\begin{abstract}
Background: Pediatric presentations of a prostatic utricle have received only little attention. The incidence of symptomatic prostatic utricle has been reported but most cases are asymptomatic. The purpose of this study is to highlight the various clinical presentations and surgical approaches to treat a symptomatic prostatic utricle.

Results: This study includes a series of 7 cases over a period of 5 years. The diagnosis of prostatic was made on the basis of clinical presentations, ultrasonography, micturating cystourethrogram, and cystoscopy.

Of the 7 patients, the newborn patient had antenatally detected abdominal cystic mass which presented with postnatal urinary retention, 5 patients had various urinary complaints, and 1 older child with disorder of sexual differentiation (DSD) had urinary incontinence. Depending upon the grade of prostatic utricle, treatment was done in the form of laparoscopic-assisted excision in 1, laparotomy and excision in 1, perineal excision in 2, and cystoscopic fulguration in 3 patients. Postoperative period was uneventful. All the patients were followed for a period of 1-2 years. Most of them were asymptomatic except one child who had recurrent episodes of epidydimo orchitis which was treated conservatively, and he was also asymptomatic at the end of 1 year. Five patients who had associated hypospadias were observed for one year for any urinary complaints before they underwent definitive repair for hypospadias.

Conclusion: Prostatic utricle is a vestigial remnant of müllerian duct most commonly associated with posterior hypospadias. High index of suspicion for prostatic utricle in cases with recurrent urinary complaints helps in timely detection and appropriate treatment can prevent further complications. Cystoscopy and micturating cytourethrogram remains the gold standard for diagnosis.

Keywords: Prostatic utricle, Laparoscopic-assisted excision, Transperineal excision, Cystoscopy and cauterization, Hypospadias
\end{abstract}

\section{Background}

Prostatic utricle (PU) is a remnant of mullerian duct. Persistent müllerian duct in males may result in an enlarged PU (prostatic utricule) or a müllerian duct cyst [1]. Prostatic utricle arises from the prostate in the midline at proximal verumontanum level in between the ejaculatory ducts (Fig. 1). Although most of them are symptomatic, asymptomatic cases are also reported [2]. The pathological presentations of PU are variable [3]. Association of PU with severe hypospadias and intersex is high as $14-27.5 \%[1,4$, 5], approximately $11-14 \%$ are associated with proximal

\footnotetext{
*Correspondence: manjiris@yahoo.com
}

Department of Pediatric Surgery, M.S. Ramaiah Medical College, MSR Nagar, Gokula Post, Bengaluru 560054, India

\section{Springer Open}

hypospadias [6, 7]. Thus, the literature shows that the incidence of PU increases with the severity of hypospadias. About $29 \%$ of children may present with clinical symptoms in childhood due to increase in the size of PU, recurrent UTI [8], stones, epidydimo orchitis, dysuria and psedoincontinence due to trapping of urine in the pouch $[2,9]$, cystoscopy, micturating cystourethrogram (MCUG), and ultrasonography are diagnostic [10,11].

Symptomatic and enlarged PU should be actively treated [9]. The treatment is intended to relieve symptoms, preserve fertility, and prevent neoplastic degeneration [12]. The suitable approach should be based on the age,

(c) The Author(s). 2020 Open Access This article is licensed under a Creative Commons Attribution 4.0 International License, which permits use, sharing, adaptation, distribution and reproduction in any medium or format, as long as you give appropriate credit to the original author(s) and the source, provide a link to the Creative Commons licence, and indicate if changes were made. The images or other third party material in this article are included in the article's Creative Commons licence, unless indicated otherwise in a credit line to the material. If material is not included in the article's Creative Commons licence and your intended use is not permitted by statutory regulation or exceeds the permitted use, you will need to obtain permission directly from the copyright holder. To view a copy of this licence, visit http://creativecommons.org/licenses/by/4.0/. 


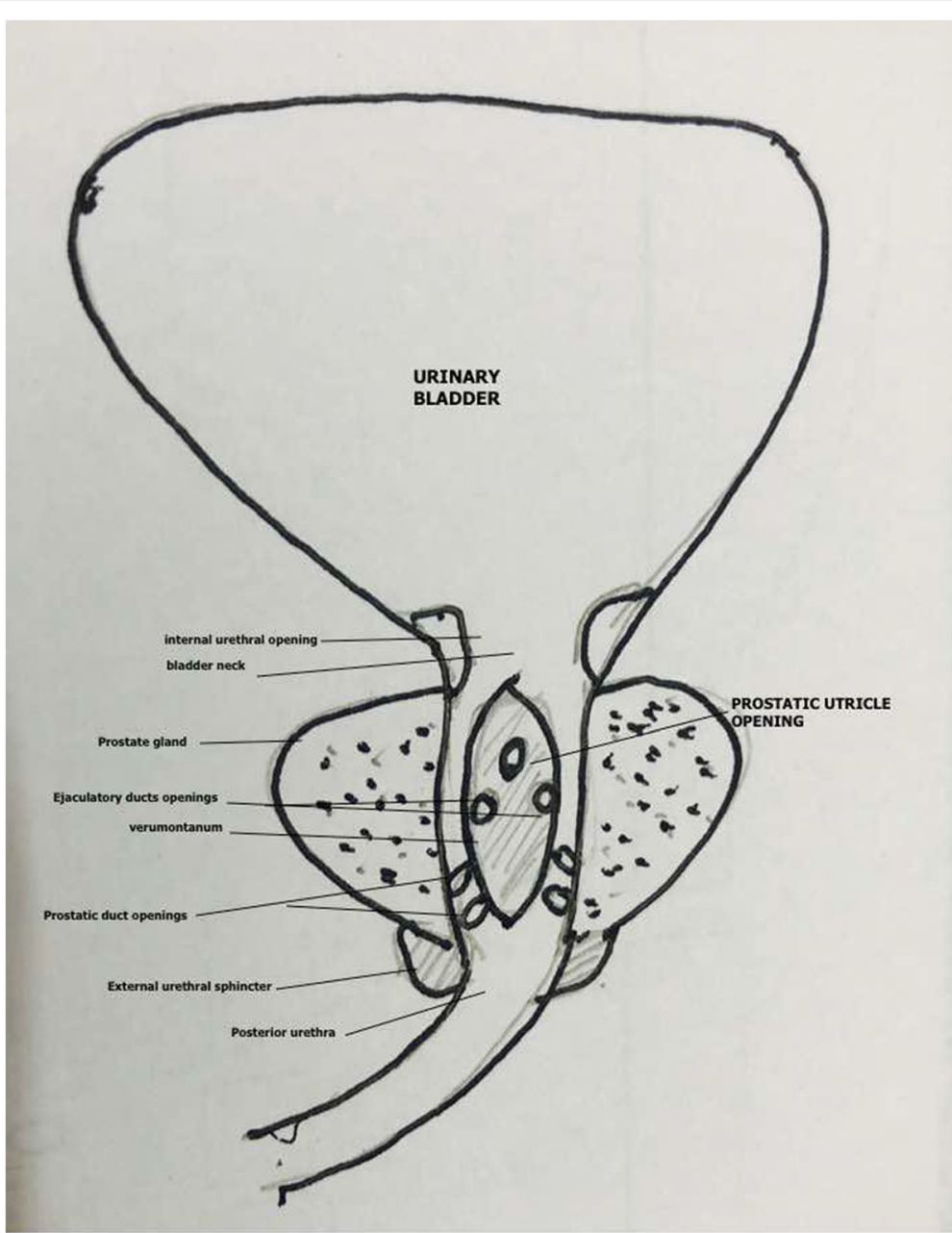

Fig. 1 Anatomy of posterior urethra showing the location of prostatic utricle (PU) opening

symptoms, and size and location of the utricle [9]. Several surgical approaches have been used in the past for the excision of PU. Various treatment approaches include abdominal transperitoneal, perineal or combined abdomino perineal, anterior or posterior sagittal transrectal, rectumretraction, suprapubic extravesical, and transvesical transtrigonal approaches $[2,9,13,14]$. Being such a rare anomaly, and given its challenging anatomical location, there has been no consensus about the best surgical approach to excise a PU [10]. Further, surgical management of PU remains challenging due to the close proximity of the lesions to ejaculatory ducts, vas deference, pelvic nerves, ureters, and rectum [1]. The complications associated with surgical approaches include urethral injury, rectal injury, infertility, impotence, and fecal incontinence [7].

The objective of this retrospective study was to highlight the importance of diagnosis of PU through various clinical presentations and varying surgical approaches to treat a symptomatic PU in children.

\section{Methods}

This retrospective study was conducted at the Department of Pediatric Surgery, Tertiary care Medical College Attached Hospital, India. Seven cases (newborn to 11 years of age) of symptomatic PU were diagnosed and managed over a period of 5 years. Informed consent was obtained from all parents/guardians. Ethical committee (EC) clearance was obtained from the institute.

Inclusion criteria was symptomatic patients diagnosed to have PU, and asymptomatic patients were excluded.

All cases were diagnosed with PU during evaluation of various urinary symptoms. The diagnosis was made on the basis of clinical presentations, cystoscopy, MCUG, and USG. Cystoscopy was used for diagnosis in 4 cases (case $n^{\circ} 2,4,5$, and 7), MCUG in 6 cases (case $n^{\circ} 1,2,3,4,6$, and 7), and USG in 1 case (case $n^{\circ} 1$ ). The size of the PU was graded as per Ikoma and colleagues classification [4] (Fig. 2).

Grade 0: opening located on the posterior urethra but the utricle does not extend over the verumontanum; 

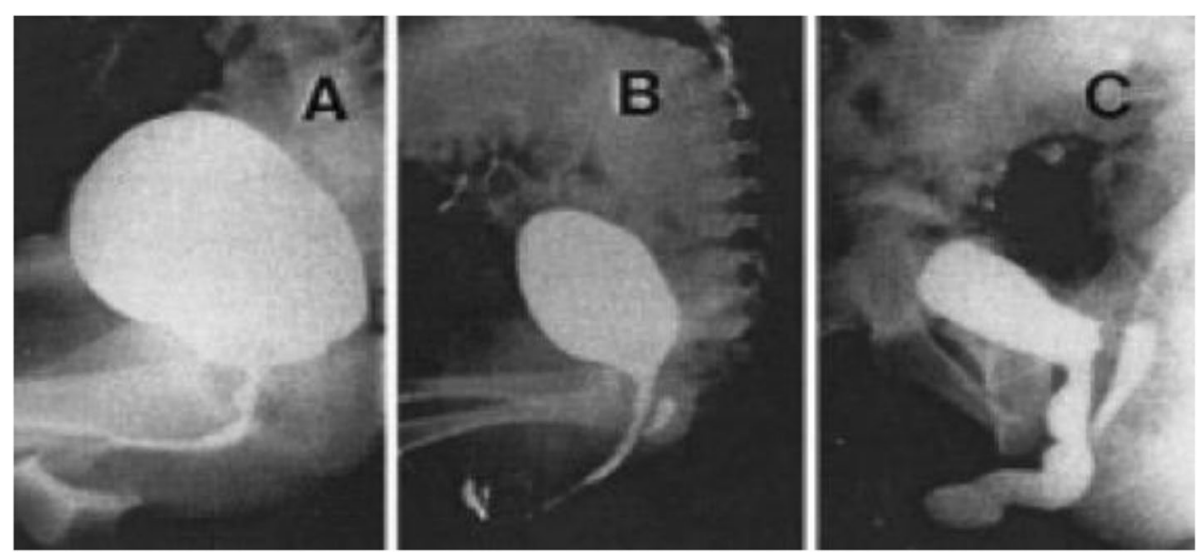

Fig. 2 Classification of enlarged prostatic utricle (PU). a Grade 0 opening located at posterior urethra, does not extend beyond the verumontenum. b Grade I Larger than grade 0, but does not reach the bladder neck. c Grade II Enlarged PU extends over the bladder neck

Grade I: larger than grade 0 but it does not reach bladder neck;

Grade II: more enlarged and its dome extends over the bladder neck (PU opens into the central area of the verumontanum in the prostatic urethra in grades 0 , I, and II);

Grade III: opening is situated in the bulbous urethra just distal to the external sphincter (in rare cases).

Various treatment modalities were used depending on clinical presentation, cystoscopy, MCUG, and USG findings. The management protocol which is explained in Fig. 3 was followed for our cases. The definitive treatment was individualized as mentioned in Table 1. Case 1 was the newborn baby with urinary retention diagnosed to have intra-abdominal cystic mass underwent diagnostic laparoscopy, due to technical difficulties it was converted to open surgery. In this child, laparotomy was done; after aspirating the cyst, it was dissected behind the bladder neck as low as possible and neck of the cyst was transfixed with absorbable 4-0 suture, and excision of the PU cyst was done. Case 2 was a child with DSD who underwent laparoscopically assisted excision of PU through midline perineal incision; urethra was repaired over the catheter using absorbable 4-0 suture. Cases 4 and 7 underwent perineal excision of PU through a midline perineal incision; the PU neck was approached and transfixed with absorbable 4-0 suture. The rest of the PU was dissected and excised. Cases 3, 5, and 6 underwent cystoscopic fulguration of the PU opening and the mucosa using bugbee electrode, since the opening was wide enough to insert $8 \mathrm{Fr}$ cystoscope.

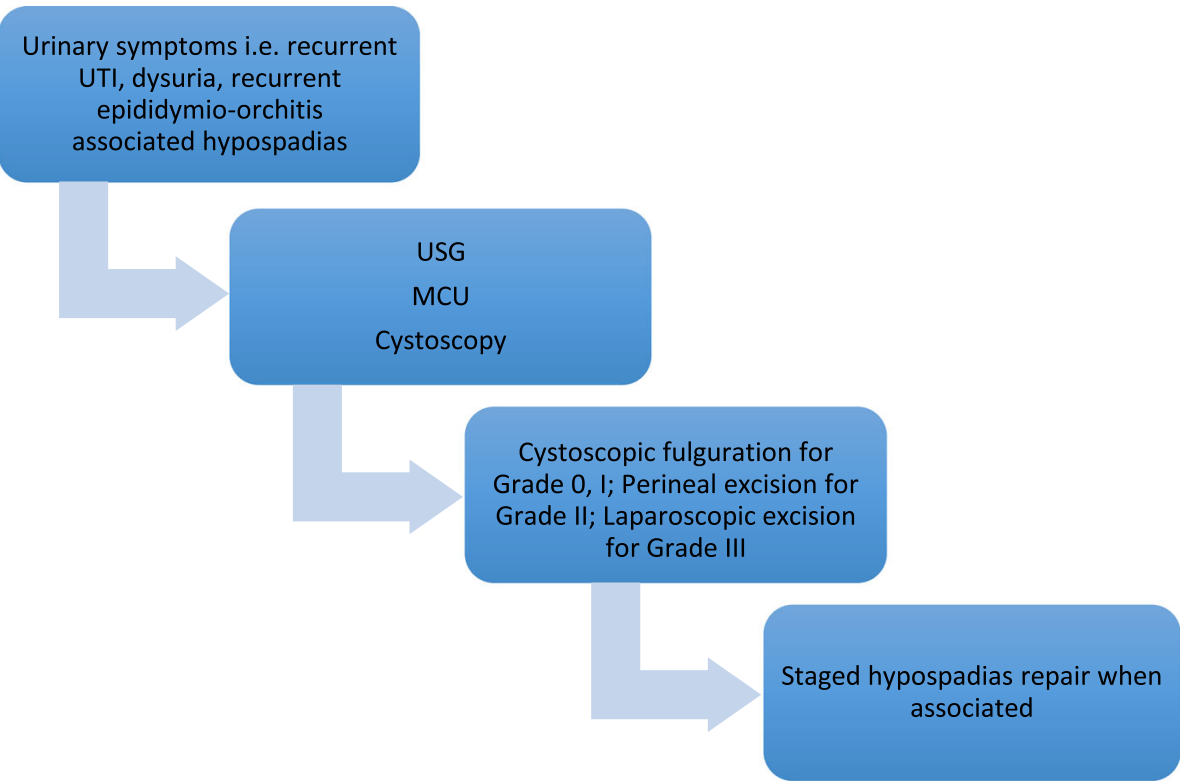

Fig. 3 Approach to symptomatic prostatic utricle (PU) 
Table 1 Clinical presentations and surgical approaches to treat a symptomatic prostatic utricle

\begin{tabular}{|c|c|c|c|c|}
\hline Case $\mathrm{n}^{\circ}$ & Age & Presentation & Investigation & Treatment \\
\hline Case 1 & Newborn & $\begin{array}{l}\text { Antenatally detected abdominal mass with } \\
\text { hydronephrosis with postnatal urinary retention }\end{array}$ & $\begin{array}{l}\text { Postnatal USG: cystic } \\
\text { abdominopelvic mass, } \\
\text { MCUG: PU with grade 3, Lt VUR }\end{array}$ & Laparotomy and excision of PU cyst \\
\hline Case 2 & 11 years & DSD 46XY, perineal hypospadias with PU & $\begin{array}{l}\text { MCUG: } 4 \times 2 \mathrm{~cm} \text { grade } 3 \mathrm{PU} \text {. } \\
\text { Cystoscopy: grade } 3 \mathrm{PU}\end{array}$ & $\begin{array}{l}\text { Laparoscopy-assisted perineal excision of } \\
\text { PU }\end{array}$ \\
\hline Case 3 & 2 years & $\begin{array}{l}\text { Penoscrotal hypospadias with severe chordee, } \\
\text { severe dysuria }\end{array}$ & $\begin{array}{l}\text { MCUG: grade } 1 \text { PU } \\
\text { cystoscopy }\end{array}$ & $\begin{array}{l}\text { Cystoscopy and cauterization } \\
\text { of the PU }\end{array}$ \\
\hline Case 4 & 2 years & $\begin{array}{l}\text { Penoscrotal hypospadias with recurrent UTI, } \\
\text { epididymo-orchitis }\end{array}$ & MCUG: grade 2 PU cystoscopy & Perineal excision of PU \\
\hline Case 5 & 4 years & Penoscrotal hypospadias, C/O dysuria & MCUG: grade 2 PU, cystoscopy & Cystoscopy and fulguration \\
\hline Case 6 & 2 years & $\begin{array}{l}\text { KVC/O ARM with DA, with mild chordee, recurrent } \\
\text { UTI and epididymo-orchitis }\end{array}$ & $\begin{array}{l}\text { MCUG: grade } 2 \text { PU } \\
\text { cystoscopy }\end{array}$ & Cystoscopy and fulguration \\
\hline Case 7 & 2 years & Perineal hypospadias, recurrent UTI & $\begin{array}{l}\text { MCUG: grade } 2 \text { PU } \\
\text { cystoscopy }\end{array}$ & Perineal excision of PU \\
\hline
\end{tabular}

DSD disorders of sex development, MCUG micturating cystourethrogram, $n^{\circ}$ number, $P U$ prostatic utricle, USG ultrasonography, UTI urinary tract infection, VUR vesicoureteral reflux, $A R M$ anorectal malformation, $D A$ duodenal atresia

\section{Results}

A total of 7 cases of symptomatic PU (newborn to 11 years of age with mean age of 3.2 years) were encountered over period of 5 years. Variable clinical presentations were encountered (Table 1). One case (case $n^{\circ} 1$ ) was diagnosed in newborn period presented with antenatally detected abdominal mass with hydronephrosis with postnatal urinary retention. MCUG in this case showed a huge cystic mass arising from junction of bulbar and prostatic urethra. The abdominal cyst reduced in size after perurethral catheterization. Cystoscopy confirmed the opening of the cyst in the proximal bulbar urethra. Five cases (case $n^{\circ} 2$, $3,4,5$, and 7) were associated with perineal or penoscrotal hypospadias and severe chordee, recurrent UTI, and severe dysuria. Two cases (case $n^{\circ} 4$ and 6) had recurrent epididymo-orchitis. Figure 4 depicts MCUG of a child (case 4) with recurrent epididymo-orchitis showing grade $2 \mathrm{PU}$ and post-void film showing retention of dye in PU pouch. Figure 2 shows the classification of PU as per the grades observed. Cystoscopy was done in all patients to confirm the position of the opening.

Per urethral catheters were removed after 5 to 7 days of procedure. All 7 cases were followed up for the period of 1 to 2 years. Except one child who initially had recurrent epididymo-orchitis, all patients have remained well on regular follow-up. All cases made an uneventful recovery from surgery. None of them experienced further episodes of urinary complaints to date. Patients with associated hypospadias eventually underwent staged repair, after 1 year of symptom-free follow-up.

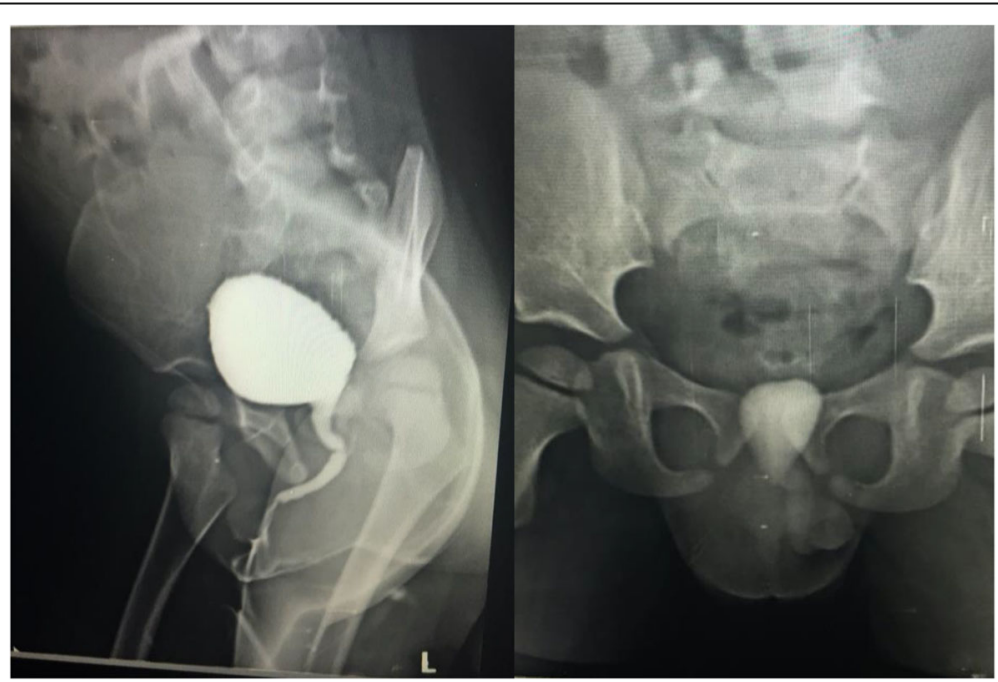

Fig. 4 Micturating cystourethrogram (MCUG) showing the prostatic utricle (PU) and retained dye in the pouch in post void film 


\section{Discussion}

Prostatic utricle is a rudimentary structure in the posterior urethra of males. It is an embryological remnant, 4- to 6-mm long opening between two ejaculatory ducts on verumontanum. It denotes the caudal end of fused müllerian duct, conforming to vaginal and cervical portion of the duct [15]. The utricle abnormalities occur due to an inadequate regression of müllerian duct or inadequate urogenital sinus closure caused by inappropriate production or sensitivity to testosterone or müllerian inhibiting substance leading to PU among various stages of hypospadias, intersex, and cryptorchidism [15]. It may also occur due to a transient decline in the fetal testicular utility during the phase of urethral formation of fetal life [6]. The utricular pouch is described as vagina musculina in cases with intersex wherein female internal organs like rudimentary uterus and fallopian tube are also present [13]. A PU is a relatively common observation in male hypospadias and its frequency seems to increase with the severity of the disorder [16, 17]. The distinction diagnosis may include severe hypospadias with or without accompanying intersex, male pseudohermaphroditism, mixed gonadal dysgenesis, or true hermaphroditism [5]. Symptomatic PU with normal external genitalia is still more challenging to diagnose due to irregularity in the presenting symptoms [9]. The management of such remnants requires a skill for complete excision and preserving fertility [12].

The clinical symptoms of PU includes urinary tract irritative symptoms, post-void dribbling, urethral discharge, stones in the utricle pouch, recurrent UTIs, recurrent epididymo-orchitis, pseudo-incontinence, and rarely outlet obstruction or malignancy in PU $[2,9,12]$. In our study, 5 cases were with severe hypospadias, chordee, recurrent UTI, and dysuria, 2 cases were with recurrent epididymoorchitis, and 1 case was with antenatally detected abdominal mass with hydronephrosis with postnatal urinary retention are observed.

Cystoscopy and MCUG are gold standard for diagnosis that helps to plan the treatment in such cases $[11,18]$. Cystoscopy facilitates complete excision of the PU [10]. The MCUG demonstrates the lower urinary tract and helps to detect vesicoureteral reflux (VUR), bladder pathology, congenital, or acquired anomalies of bladder [19]. The diagnosis can also be made using USG [11]. It may add complementary information about the morphology of the PU and it is reported to be noninvasive and painless [16]. In our study, cystoscopy, MCUG and USG were diagnostic for PU in all the 7 cases. Sometimes during hypospadias repair inability to introduce catheter into the bladder reveals the presence of PU. In such cases, PU should be treated first and hypospadias repair should be done at a later stage. Recurrent episodes of epididymo-orchitis due to enlarged PU are attributed to the obstruction of ejaculatory ducts which open on either side of the verumontanum (Fig. 1).

The PU is classified into four types from the perspective of size and location of the opening of the utricle. Ikoma and colleagues devised grading system (grade 0 , grade I, grade II, and grade III) for PU with hypospadias. The higher grades (grade II and grade III) are seen more often in patients with severe hypospadias [4]. In our study, 2 cases had grade $3 \mathrm{PU}, 1$ case had grade $1 \mathrm{PU}$, and 4 cases had grade 2 PU. This confirmed a direct relationship between the degree of hypospadias and the increasing size of the PU.

Various approaches have been described for surgical intervention in PUs [12]. A flowchart proposing management protocol for symptomatic PU cases is presented in Fig. 3. Prostatic utricle have traditionally been excised via the open approach or laparoscopically $[12,20]$. Other surgical approaches include abdominal extravesical, transtrigonal, suprapubic, extravesical transperineal, parasacral, retropubic, transanorectal anterior or posterior sagittal approach [14], transurethral deroofing, and endoscopic fulguration. However, these approaches can be challenging and involve complications. All these approaches require extensive dissection, often requiring two stages and result in poor exposure. Most common complication are incontinence, infections, and impotence secondary to injury to pelvic nerves $[6,7,12,15]$.

Laparoscopic approach for the excision of PU has been successful in children [21, 22]. Schuhrke and Kaplan described endoscopic transurethral cyst catheterization and aspiration, cyst orifice dilatation, or incision and deroofing, and reported that it is well suited to this problem [23]. Ahmad and Palmer reported successful transperineal cyst aspiration and sclerotherapy with tetracycline under transracial ultra sound guidance [24]. In our study, one case underwent laparoscopy-assisted perineal excision of the PU and reaffirms the benefits of laparoscopy in these deep pelvic anomalies. Three cases successfully underwent cystoscopic cauterization. One case underwent laparotomy and excision of the PU cyst while two cases underwent perineal approach for excision of PU. The removal of the utricle with our approaches ended the urinary symptoms. All 7 cases were followed up for the period of 1 to 2 years. Except one child who initially had recurrent epididymo-orchitis, who eventually became asymptomatic with conservative management. All cases have been asymptomatic.

The clinical presentations and various surgical approaches used to treat PU in children in various clinical studies from other researchers are summarized in Table 2. 
Table 2 Various studies reporting clinical presentations and treatment approaches for treatment of prostatic utricle

\begin{tabular}{|c|c|c|c|c|c|}
\hline Observations & Our series & $\begin{array}{l}\text { Hester and } \\
\text { Kogan [2] }\end{array}$ & Liu et al. [9] & Ikoma et al. [13] & Meisheri et al. [14] \\
\hline $\begin{array}{l}\text { No. of } \\
\text { patients }\end{array}$ & 7 & 31 & 22 & 14 & 6 \\
\hline Age & Newborn-11 years & 2.1 years mean & 2 months- 18 years & $2-28$ years & 10 months-10 years \\
\hline $\begin{array}{l}\text { Presenting } \\
\text { symptoms }\end{array}$ & $\begin{array}{l}\text { Recurrent UTI, } \\
\text { epididymo-orchitis }\end{array}$ & $\begin{array}{l}\text { UTI, urinary } \\
\text { obstruction, dysuria }\end{array}$ & $\begin{array}{l}\text { Pyuria, retention of urine, } \\
\text { epididymo-orchitis, } \\
\text { hematuria, cystic mass in } \\
\text { pelvis, calculus formation, } \\
\text { malignancy }\end{array}$ & $\begin{array}{l}\text { Recurrent UTI, } \\
\text { post-void dribbling } \\
\text { of urine }\end{array}$ & $\begin{array}{l}\text { Recurrent UTI, } \\
\text { epididymo-orchitis, } \\
\text { pyuria, one child had } \\
\text { renal failure }\end{array}$ \\
\hline $\begin{array}{l}\text { Associated } \\
\text { anomalies }\end{array}$ & Severe hypospadias-6 & $\begin{array}{l}\text { Hypospadias-8, } \\
\text { cryptorchidism-7 }\end{array}$ & $\begin{array}{l}\text { Unilateral renal agenesis, } \\
\text { posterior urethral valve, VUR }\end{array}$ & $\begin{array}{l}\text { Severe hypospadias-14, } \\
\text { also MGD in } 6\end{array}$ & Severe hypospadias-5 \\
\hline Investigations & MCUG, USG, cystoscopy & Cystoscopy, VCUG & $\begin{array}{l}\text { USG, cystoscopy, IVP, VCUG, } \\
\text { RUG CT, and MRI }\end{array}$ & MCUG & MCUG, RUG, cystoscopy \\
\hline $\begin{array}{l}\text { Treatment } \\
\text { approaches }\end{array}$ & $\begin{array}{l}\text { Cystoscopic fulguration, } \\
\text { laparoscopic-assisted } \\
\text { perineal excision, } \\
\text { transperineal excision, } \\
\text { trans abdominal excision }\end{array}$ & $\begin{array}{l}\text { Endoscopic } \\
\text { fulguration and } \\
\text { obliteration with } \\
\text { tissue sealant, } \\
\text { open excision }\end{array}$ & $\begin{array}{l}\text { Trans rectal USG-guided } \\
\text { aspiration, endoscopic } \\
\text { techniques, open excision, } \\
\text { laparoscopic- and } \\
\text { robotic-assisted excision }\end{array}$ & $\begin{array}{l}\text { Abdominal, abdomino } \\
\text { perineal, transperineal } \\
\text { and transvesical } \\
\text { approaches for open } \\
\text { excision }\end{array}$ & $\begin{array}{l}\text { Posterior sagittal approach, } \\
\text { transvesical and combined } \\
\text { posterior sagittal and } \\
\text { abdominal approach for } \\
\text { open excision }\end{array}$ \\
\hline
\end{tabular}

Abbreviations: CT computerized tomography, IVP intravenous pyelogram, MCUG, micturating cystourethrogram, MGD mixed gonadal dysgenesis, MRI magnetic resonance imaging, RUG retrograde urethrogram, USG ultrasonography, UTI urinary tract infection, VCUG voiding cystourethrogram

\section{Conclusion}

Prostatic utricle should be considered as one of the differential diagnosis in children with recurrent urinary complaints as it assures early detection and management, more so with severe hypospadias, although isolated PU are also known. MCUG and cystoscopy are hence recommended in all cases of severe hypospadias as preoperative workup before planning hypospadias repair. The ideal surgical approach requires accurate diagnosis of the location of PU. Missed or delayed diagnosis of PU can lead to fatal consequences like renal failure; hence, it is important to diagnose PU in time and treat appropriately.

\section{Abbreviations \\ CT: Computerized tomography; DSD: Disorders of sex development; EC: Ethical committee; IVP: Intravenous pyelogram; LUTS: Lower urinary tract symptoms; MCUG: Micturating cystourethrogram; MGD: Mixed gonadal dysgenesis; MRI: Magnetic resonance imaging; $n^{\circ}$ : Number; PU: Prostatic utricle; RUG: Retrograde urethrogram; USG: Ultrasonography; UTI: Urinary tract infection; VCUG: Voiding cystourethrogram; VUR: Vesicoureteral reflux}

\section{Acknowledgements}

We acknowledge the cooperation of our patients and their parents/ guardians for giving us consent for this study.

\section{Authors' contributions}

Author MS has contributed by compiling the data and writing the manuscript. KL has contributed to collect the clinical data. JS has contributed by providing clinical photographs. PK and NP have collected the references and literature review. All the authors have read and approved the revised manuscript for submission

\section{Funding}

No funding source to declare.

\section{Availability of data and materials}

The data that support the findings of this study were collected from the hospital records and the availability of this data is restricted, however it can be obtained on request from the hospital authorities.
Ethics approval and consent to participate

This study is approved by the Ethics Committee (EC) of Ramaiah Medical College, Bengaluru, India (Reg. No. ECR/215/Inst/KA/2013/RR-19). Informed verbal as well as written consent for publication of the data and photos have been obtained from the parents of the patients included in this study as per the institution's rule.

\section{Consent for publication \\ Not applicable}

\section{Competing interests}

The authors declare that they have no competing interests.

Received: 1 May 2020 Accepted: 10 November 2020

Published online: 09 December 2020

\section{References}

1. Priyadarshi V, Singh JP, Mishra S, Vijay MK, Pal DK, Kundu AK. Prostatic utricle cyst: a clinical dilemma. APSP J Case Rep. 2013;4(2):16.

2. Hester AG, Kogan SJ. The prostatic utricle: An under-recognized condition resulting in significant morbidity in boys with both hypospadias and normal external genitalia. J Pediatr Urol. 2017;13(5):492.e1-5.

3. Oh CS, Chung $\mathrm{H}$, Won HS, Kim JH, Nam Kl. Morphologic variations of the prostatic utricle. Clin Anat. 2009;22(3):358-64.

4. Ikoma F, Shima H, Yabumoto H. Classification of enlarged prostatic utricle in patients with hypospadias. Br J Urol. 1985;57(3):334-7.

5. Devine CJ Jr, Gonzalez-Serva L, Stecker JF Jr, Devine PC, Horton CE. Utricular configuration in hypospadias and intersex. J Urol. 1980;123:407-11.

6. Jiwane A, Soundappan SV, Pitkin J, Cass DT. Successful treatment of recurrent epididymo-orchitis: Laparoscopic excision of the prostatic utricle. J Indian Assoc Pediatr Surg. 2009;14(1):29-30.

7. Kumar V, Punatar C, Jadhav K, Sagade S. Accidental cystectomy during laparoscopic excision of prostatic utricle cyst - a rare complication. Int Braz J Urol. 2018;44(4):826-30.

8. Jia W, Liu GC, Zhang LY, Wen YQ, Fu W, Hu JH, Xia HM. Comparison of laparoscopic excision versus open transvesical excision for symptomatic prostatic utricle in children. J Pediatr Surg. 2016;51(10):1597-601.

9. Liu B, He D, Zhang D, Liu X, Lin T, Wei G. Prostatic utricles without external genital anomalies in children: our experience, literature review, and pooling analysis. BMC Urol. 2019;19(1):21.

10. Mostafa IA, Woodward MN, Shalaby MS. Cystoscopic-assisted laparoscopic excision of prostatic utricle. J Pediatr Urol. 2018;14(1):77-8. 
11. Mosa H, Mishra P. Rendezvous cystoscopy-laparoscopy for excision of a prostatic utricle with an ectopically inserted ureter. J Pediatr Endosc Surg. 2020:1-2.

12. Lima M, Maffi M, Di Salvo N, Ruggeri G, Libri M, Gargano T, Lardy H. Robotic removal of Müllerian duct remnants in pediatric patients: our experience and a review of the literature. Pediatr Med Chir. 2018;40(1):27-30.

13. Ikoma F, Shima H, Yabumoto H, Mori Y. Surgical treatment for enlarged Prastatic utricle and vagina masculine in patients with hypospadias. $\mathrm{Br} J$ Urol. 1986;58(4):423-8.

14. Meisheri IV, Motiwale SS, Sawant W. Surgical management of enlarged prostatic utricle. Pediatr Surg Int. 2000;16(3):199-203.

15. Ramachandra M, Bendre PS, Redkar RG, Taide DV. Isolated prostatic utricle. J Indian Assoc Pediatr Surg. 2009;14(4):228-9.

16. Kojima Y, Hayashi Y, Maruyama T, Sasaki S, Kohri K. Comparison between ultrasonography and retrograde urethrography for detection of prostatic utricle associated with hypospadias. Urology. 2001;57(6):1151-5.

17. Currarino G. Large prostatic utricles and related structures, urogenital sinus and other forms of urethrovaginal confluence. J Urol. 1986;136(6):1270-9.

18. Tse KS, Wong LS, Lau HY, Fok WS, Chan YH, Tang KW, Chan SC. Paediatric vesicoureteric reflux imaging: where are we? Novel ultrasound-based voiding urosonography. Hong Kong Med J. 2014;20(5):437-43.

19. Al-Imam OA, Moh'd Al-Nsour N, Al-Khulaifat S. Which is the best way of performing a micturating cystourethrogram in children? Saudi J Kidney Dis Transpl. 2008;19(1):20.

20. Nguyen A, Arora H, Reese J, Kaouk J, Rhee A. Robot-assisted laparoscopic excision of prostatic utricle in a 3-year old. J Pediatr Urol. 2018;14(4):343-4.

21. Yeung CK, Sihoe JD, Tam YH, Lee KH. Laparocopic excision of prostatic utricles in children. BJU Int. 2001;87:505-8.

22. Willets IE, Roberts JP, McKinnon AE. Laparoscopic excision of prostatic utricle in child. Pediatr Surg Int. 2003;19:557-8.

23. Schuhrke TD, Kaplan GW. Prostatic utricle cysts (müllerian duct cysts). J Urol. 1978;119(6):765-7.

24. Ahmed M, Palmer JW. Large symptomatic Mullerian duct cyst treated by tetracycline sclerotherapy. Int Urol Nephrol. 1995;27:193.

\section{Publisher's Note}

Springer Nature remains neutral with regard to jurisdictional claims in published maps and institutional affiliations.

\section{Submit your manuscript to a SpringerOpen ${ }^{\circ}$ journal and benefit from:}

- Convenient online submission

- Rigorous peer review

- Open access: articles freely available online

- High visibility within the field

- Retaining the copyright to your article

Submit your next manuscript at $\boldsymbol{\nabla}$ springeropen.com 